\title{
Red wine and component flavonoids inhibit UGT2B17 in vitro
}

\author{
Carl Jenkinson, Andrea Petroczi and Declan P Naughton*
}

\begin{abstract}
Background: The metabolism and excretion of the anabolic steroid testosterone occurs by glucuronidation to the conjugate testosterone glucuronide which is then excreted in urine. Alterations in UGT glucuronidation enzyme activity could alter the rate of testosterone excretion and thus its bioavailability. The aim of this study is to investigate if red wine, a common dietary substance, has an inhibitory effect on UGT2B17.

Methods: Testosterone glucuronidation was assayed using human UGT2B17 supersomes with quantification of unglucuronidated testosterone over time using HPLC with DAD detection. The selected red wine was analyzed using HPLC; and the inhibitory effects of the wine and phenolic components were tested independently in a screening assay. Further analyses were conducted for the strongest inhibitors at physiologically relevant concentrations. Control experiments were conducted to determine the effects of the ethanol on UGT2B17.

Results: Over the concentration range of 2 to $8 \%$, the red wine sample inhibited the glucuronidation of testosterone by up to $70 \%$ over 2 hours. The ethanol content had no significant effect. Three red wine phenolics, identified by HPLC analyses, also inhibited the enzyme by varying amounts in the order of quercetin (72\%), caffeic acid (22\%) and gallic acid (9\%); using a ratio of phenolic:testosterone of 1:2.5. In contrast p-coumaric acid and chlorogenic acid had no effect on the UGT2B17. The most active phenolic was selected for a detailed study at physiologically relevant concentrations, and quercetin maintained inhibitory activity of $20 \%$ at $2 \mu \mathrm{M}$ despite a ten-fold excess of testosterone.

Conclusion: This study reports that in an in vitro supersome-based assay, the key steroid-metabolizing enzyme UGT2B17 is inhibited by a number of phenolic dietary substances and therefore may reduce the rate of testosterone glucuronidation in vivo. These results highlight the potential interactions of a number of common dietary compounds on testosterone metabolism. Considering the variety of foodstuffs that contain flavonoids, it is feasible that diet can elevate levels of circulating testosterone through reduction in urinary excretion. These results warrant further investigation and extension to a human trial to delineate the health implications.
\end{abstract}

Keywords: Red wine, Flavonoids, Testosterone, UGT2B17, Glucuronidation

\section{Introduction}

Numerous reports have attested to the health damaging effects of red wine and its components beyond excess alcohol consumption, for example - owing to pesticide and heavy metal content [1,2]. In contrast, many reports point to the health protective effects of red wine owing to the abundance of anti-oxidants [3,4]. Beyond modulating oxidative damage, one focus has been on the female endocrine system, following the reports that red

\footnotetext{
* Correspondence: D. Naughton@kingston.ac.uk

School of Life Sciences, Kingston University, Penrhyn Road, Kingston upon

Thames, London, Surrey KT1 2EE, UK
}

\section{Biomed Central}

(c) 2012 Jenkinson et al.; licensee BioMed Central Ltd. This is an Open Access article distributed under the terms of the Creative Commons Attribution License (http://creativecommons.org/licenses/by/2.0), which permits unrestricted use, distribution, and reproduction in any medium, provided the original work is properly cited. wine has anti-aromatase properties [5]. This discovery broadened the debate regarding the link between alcohol intake and risk of developing breast cancer $[6,7]$.

Equally, the associations of high and low testosterone levels with the development of various forms of prostate cancer have been subjected to considerable debate [8-10]. Given the inhibitory effects of red wine on aromatase it is conceivable that red wine also affects aspects of testosterone metabolism. Although recent epidemiological studies have suggested red wine consumption is not a potential risk factor 
for prostate cancer $[11,12]$, the effects of red wine on testosterone metabolism warrant investigation.

Glucuronidation is a major metabolic pathway for the elimination of testosterone and numerous compounds from the body $[13,14]$. Glucuronidation of testosterone involves the transfer of a glucuronosyl group from UDPglucuronic acid (UDPGA) to form the steroid conjugate, testosterone glucuronide, which is then excreted in urine [13]. The UDP-glucuronosyltranferase UGT2B17 enzyme is the main steroid glucuronidation enzyme of the UGT isotopes with more than double the glucuronidation activity compared to the second most active enzyme involved in glucuronidation of testosterone, UGT2A1 [15].

The metabolism of testosterone by UGT2B17 has been shown to differ between individuals owing to the variations in the expression of UGT2B17, which has been found to alter with ethnicity, affecting the excreted steroid concentrations [16]. In in vitro studies, the rate of testosterone glucuronidation has also been shown to be reduced with inhibitors of UGT2B17, such as non-steroidal anti-inflammatory drugs [15]. Whilst various drugs and compounds are glucuronidated as a substrate and inhibit UGT2B17 [13], little is known about the inhibitory effects common dietary substances could have on UGT2B17 and testosterone glucuronidation.

Recently, green and white teas and purified catechin constituents have been shown to inhibit the key testosterone glucuronidation enzyme UGT2B17 in a supersome-based assay [17]. Red wine is another rich source of phenolic compounds that have been found to exert anti-oxidant health benefits in humans [18]. Given the inhibitory effects of green and white tea on UGT2B17, along with the debate on red wine and prostate cancer, it is timely to investigate if phenolic compounds in red wine have an inhibitory effect on testosterone metabolism and excretion.

The aim of this study was to analyze the inhibitory effects of a dietary red wine sample and the common phenolic compounds found in red wine, independent of the effects of alcohol, on the glucuronidation of testosterone through the inhibition of UGT2B17. A further aim was to study the potential inhibitory effect of the common wine by-product 4-ethylphenol on testosterone glucuronidation.

\section{Materials and methods Materials}

Testosterone, acetonitrile, ethanol, gallic acid, chlorogenic acid, caffeic acid and quercetin were purchased from Sigma Aldrich (Poole, United Kingdom). Dimethyl sulfoxide, methanol and high performance liquid chromatography (HPLC) grade water were purchased from Fisher Scientific. The UGT2B17 enzymes where purchased as human
UGT2B17 supersomes from BD Biosciences. UDPGA was purchased as a UGT reaction solution (mixture A) from BD Biosciences. The $\mathrm{MgCl}_{2}$ and Tris- $\mathrm{HCl}$ buffers, along with alamethicin were purchased together as a UGT reaction mixture (solution B) from BD Biosciences. The red wine sample used was a Cabernet-Syrah red wine purchased from a local supermarket (London). All solvents used where HPLC grade.

\section{Methods}

For general screening, HPLC analysis of testosterone glucuronidation was conducted on an Agilent 1260 HPLC system using an Ascentis Supelco C18 column, $25 \mathrm{~cm} \mathrm{x} 406 \mathrm{~mm}$ i.d., $5 \mu \mathrm{M}$ at $25^{\circ} \mathrm{C}$ column temperature. The mobile phase was methanol and water $(80: 20)$ at a flow rate of $1 \mathrm{~mL} / \mathrm{min}$ and a $100 \mu \mathrm{L}$ injection volume. The remaining testosterone from the reactions was detected by UV detection at $246 \mathrm{~nm}$ using a diode array detection system. The results represent the SD of duplicate values.

To assay the effects of quercetin at low concentrations, an alternate highly sensitive HPLC method was adopted to analyze testosterone [19]. Testosterone was dissolved in acetonitrile and added as $1 \% \mathrm{v} / \mathrm{v}$. The mobile phase was acetonitrile/water $(39 / 61, \mathrm{v} / \mathrm{v})$ at a flow rate of $1 \mathrm{~mL} / \mathrm{min}$. The injection volume was $50 \mu \mathrm{L}$ and detection at $245 \mathrm{~nm}$. The results represent the SD of triplicate values.

The testosterone glucuronidation assay, described in the $\mathrm{BD}$ biosciences data sheet for the human UGT2B17 supersomes, employs a standard incubation mixture containing UDPGA $(2 \mathrm{mM})$, alamethicin $(25 \mu \mathrm{g} / \mathrm{mL})$, magnesium chloride $(8 \mathrm{mM})$ and $\mathrm{pH}$ 7.5 Tris- $\mathrm{HCl}$ buffer $(50 \mathrm{mM})$ and deionised water comprising $50 \%$ of the overall reaction volume. Following incubation at $37^{\circ} \mathrm{C}$ for five minutes, the reaction was initiated by the addition of $0.2 \mathrm{mg} / \mathrm{mL}$ ice cold UGT2B17 supersomes. The reactions were stopped by the transfer of $100 \mu \mathrm{L}$ aliquots to $100 \mu \mathrm{L}$ ice cold acetonitrile, vortex-mixed with samples stored on wet ice. The samples were centrifuged at $10,000 \times \mathrm{g}$ for 5 minutes. The aliquots of the supernatants were then analyzed by HPLC.

In order to study the inhibitory effects of red wine, various volumes ranging from $2-8 \%$ of red wine were added to the reaction. The reactions were stopped after one or two hours and the remaining testosterone was analyzed to determine any increase in testosterone through the inhibition by red wine. The red wine sample had been evaporated to dry residue to remove the ethanol and reconstituted with the same volume of water and filtered by a Millex $0.45 \mu \mathrm{M}$ filter device.

The phenolic compounds gallic acid, caffeic acid and quercetin that are present in red wine were analyzed for 
the inhibition of UGT2B17. The phenolic standards $(250 \mu \mathrm{M})$ were dissolved in ethanol and heated and mixed to aid dissolving where necessary and added to the reaction as $1 \% \mathrm{v} / \mathrm{v}$ of the reaction. The phenolic compound 4-ethylphenol was dissolved in ethanol and added to the reaction at $1 \%$ of the overall reaction volume at $750 \mu \mathrm{M}$ overall concentration. The reaction duration was for 1 hour.

The red wine sample used in the glucuronidation assays was analyzed to determine the phenolic compounds present in the wine. The wine sample for HPLC analysis was prepared by evaporating the sample to dryness with the remaining dry residue dissolved in water to restore the original volume of the sample. The sample was then filtered by a Millex $0.45 \mu \mathrm{M}$ filter device and injected into the HPLC. Quantification was performed as previously described [20] on an Agilent 1260 HPLC using a Kromasil C18 column, $250 \mathrm{~mm}$ x 406 mm $5 \mu \mathrm{M}$ with detection at $280 \mathrm{~nm}$. The mobile phase consisted of $0.1 \%$ orthophosphoric acid in water (A) and methanol (B). The mobile phase gradient elusions were $(80 \% \mathrm{~A}$ : $20 \%$ B) 0 minutes, $(60 \%$ A: $40 \%$ B) 10 minutes, $(50 \%$ A: $50 \%$ B) 20 minutes, (45\% A: 55\% B) 30 minutes, (35\% A: $65 \%$ B) 50 minutes. The flow rate was $1 \mathrm{~mL} / \mathrm{min}$ with a $10 \mu \mathrm{L}$ injection volume. Phenolic standards were dissolved in water at a concentration of $1 \mathrm{mg} / \mathrm{mL}$ and individually injected into the HPLC under the same conditions with the retention times compared to that of the red wine sample to indentify each phenolic compound.

Statistical analyses were conducted using SPSS v19. The significance of reduction in glucuronidation activity was tested for using a directional one-sample $t$-test $\left(\mathrm{H}_{\mathrm{a}}\right.$ : activity $<100 \%$ ) with the significance level set at 0.05 . Mixed model ANOVA was used to test for statistically significant difference over time and between concentrations, including testing for interaction effect.

\section{Results}

\section{Inhibitory effects of red wine on UGT2B17}

The effects of increasing concentrations of red wine on the UGT2B17-mediated glucuronidation of testosterone were assessed as a function of the reduction in conversion of testosterone to testosterone glucuronide (Figure 1). The results show that increasing the concentration of red wine resulted in a lower conversion of testosterone to its glucuronide conjugate. A reduction in UGT2B17 activity was observed for all, ranging between ca $10 \%$ to over $70 \%$ over two hours for additions of $2 \%$ to $8 \%$ red wine $(\mathrm{p}=0.01$; $0.002 ; 0.008$ and 0.014 over one hour and $\mathrm{p}=0.019 ; 0.033$; 0.008 and 0.007 over two hours, respectively for $2 \%, 4 \%$, $6 \%$ and $8 \%$ ). The percentage of ethanol present in the final assay was in the range of $0.26 \%-1.04 \%$ corresponding to additions of red wine at $2 \%-8 \%$ respectively. It is notable that during a 2 hour period the inhibition is more pronounced at higher concentration of the red wine. Statistically significant differences were evidenced between times $(p=0.028)$ and concentrations $(p<0.001)$, with significant interaction between the two $(\mathrm{p}=0.001)$.

The effect on UGT2B17 activity by the addition of an evaporated red wine sample reconstituted with an equal volume of water at concentrations of $4 \%$ and $8 \%$ of the reaction volume resulted in a glucuronidation \% of control at $59.18 \pm 3.154$ and $23.48 \pm 4.405$, respectively. These values, taken after a two-hour duration, resemble those from the intact wine samples (Figure 1) indicating minimal contributions from the ethanol content on the inhibition of UGT2B17 by red wine.

The effects of increasing concentrations of ethanol on the reduction of testosterone by UGT2B17 are shown in Figure 2. The results indicated that testosterone glucuronidation was only slightly altered by ethanol at a $1 \%$ concentration $(\mathrm{p}=0.353)$; however as the concentration of ethanol was increased to above $2 \%$ of the reaction volume, testosterone glucuronidation was affected as shown but not reaching a statistically significant level $(\mathrm{p}=0.134$ and 0.110 for $2 \%$ and $3 \%$, respectively).

\section{Analysis of red wine}

In order to identify individual inhibitors of UGT2B17, the phenolic content in the wine sample was investigated by HPLC. Analysis of the red wine confirmed the presence of gallic acid, chlorogenic acid, caffeic acid, pcoumaric acid and quercetin (Figure 3), which informed subsequent experiments.

\section{The inhibitory effect of individual phenolic compounds}

Initial experiments were performed to screen the phenolics found in red wine for their effects on UGT2B17. Table 1 shows the effect on the glucuronidation activity of testosterone when $250 \mu \mathrm{M}$ of each of the three phenolic compounds found in the red wine sample were added separately to the reaction over 60 minutes. Apart from chlorogenic and p-coumaric acids glucuronidation activity was reduced by each of the compounds in varying degrees. The inhibitory action of 4-ethylphenol is also displayed in Table 1 . The results show the reduction in testosterone glucuronidation at initial testosterone concentrations of $100 \mu \mathrm{M}, 50 \mu \mathrm{M}$ and $20 \mu \mathrm{M}$.

Quercetin was selected from the initial high concentration screening assay for further study as it exhibited the highest level of inhibition at $72 \%$. Reducing the testosterone levels to $20 \mu \mathrm{M}$ resulted in inhibition of $34-18 \%$ by a low concentration of quercetin, in a concentration dependent manner, despite the 10-fold excess in testosterone levels (Table 1). In addition, for a quercetin concentration of $2 \mu \mathrm{M}$, increasing testosterone levels to $30 \mu \mathrm{M}$ resulted in a 


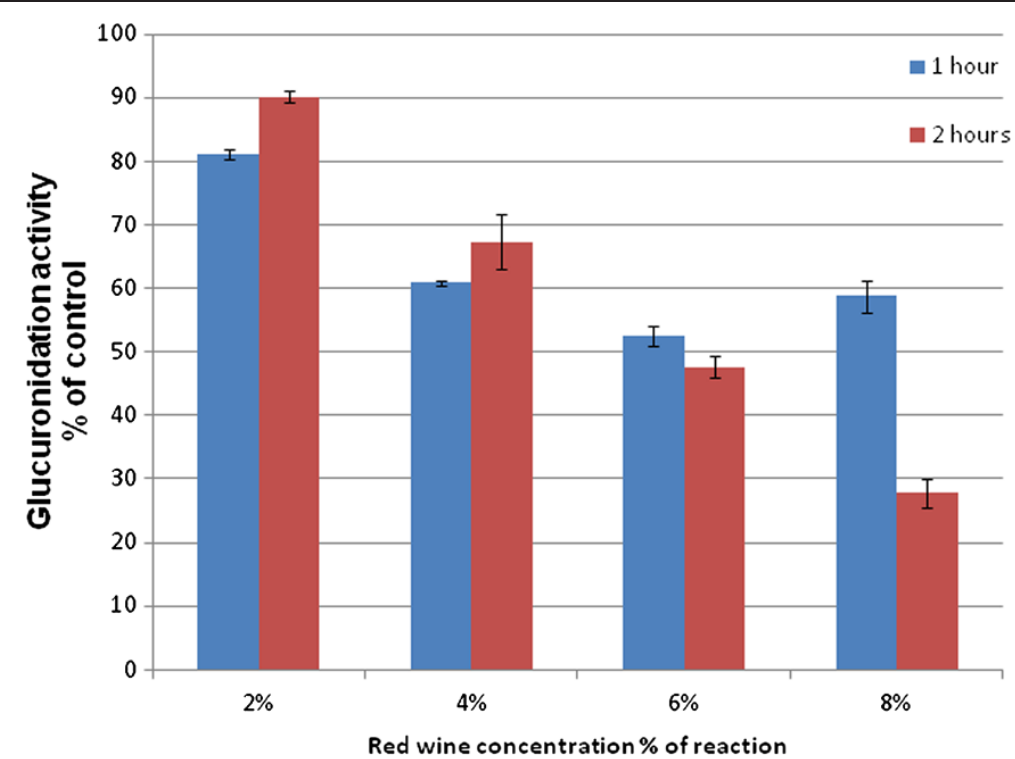

Figure 1 Reduction of testosterone glucuronidation in the presence of red wine at $100 \mu \mathrm{M}$ initial testosterone. The results display the SD values of duplicate samples.

reduction in inhibition from $18 \%$ to $2 \%$ suggesting that the mechanism is by competitive inhibition.

\section{Discussion}

This report extends the previous study which demonstrated that tea and its component flavones competitively inhibit testosterone glucuronidation by UGT2B17. The results of this study showed that phenolic compounds commonly found in red wine, but also in many other foods, have comparable effect on testosterone glucuronidation. The rate of glucuronidation was similar on addition of the wine sample once the ethanol had been removed, indicating that it was likely to be the phenolic compounds that caused inhibition. Further studies revealed that ethanol had no effect at the concentrations found in the added wine sample. However, at higher concentrations of ethanol $(>1 \%)$ the UGT2B17 enzyme activity was reduced. Ethanol has been linked to increased testosterone and aggression in male hamsters [21] and increased testosterone in rat brain [22]. From our results, the effects of alcohol on UGT2B17 are unlikely to account for the increase in testosterone, unless extremely high doses are consumed.

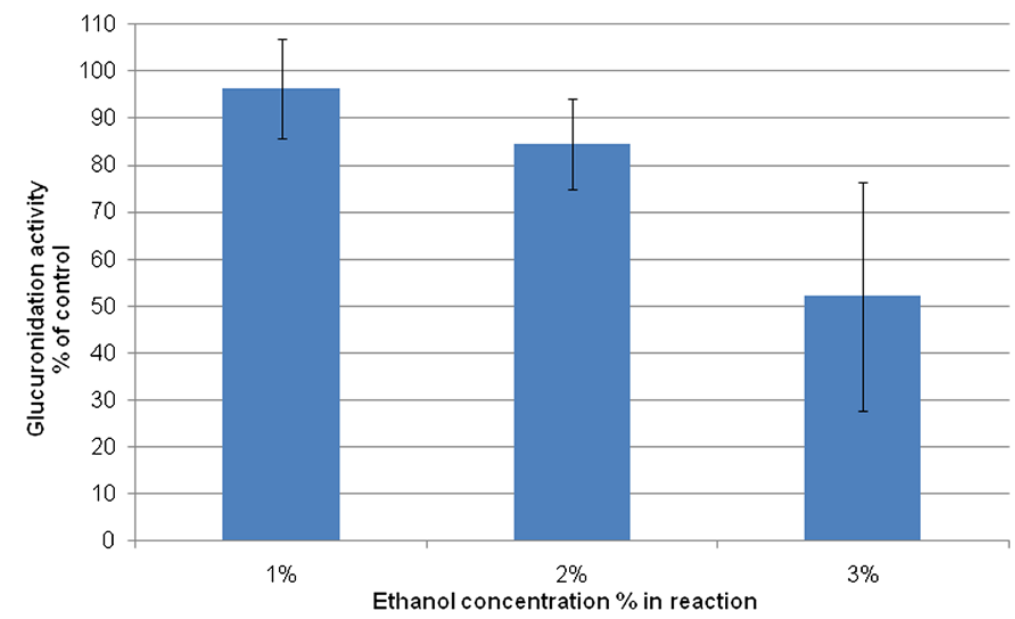

Figure 2 Effect of ethanol on the testosterone glucuronidation by UGT2B17, based on the concentration of testosterone. Concentration of testosterone was measured at the end of the reaction which was terminated after 30 minutes. The results display the SD values of duplicate samples. 


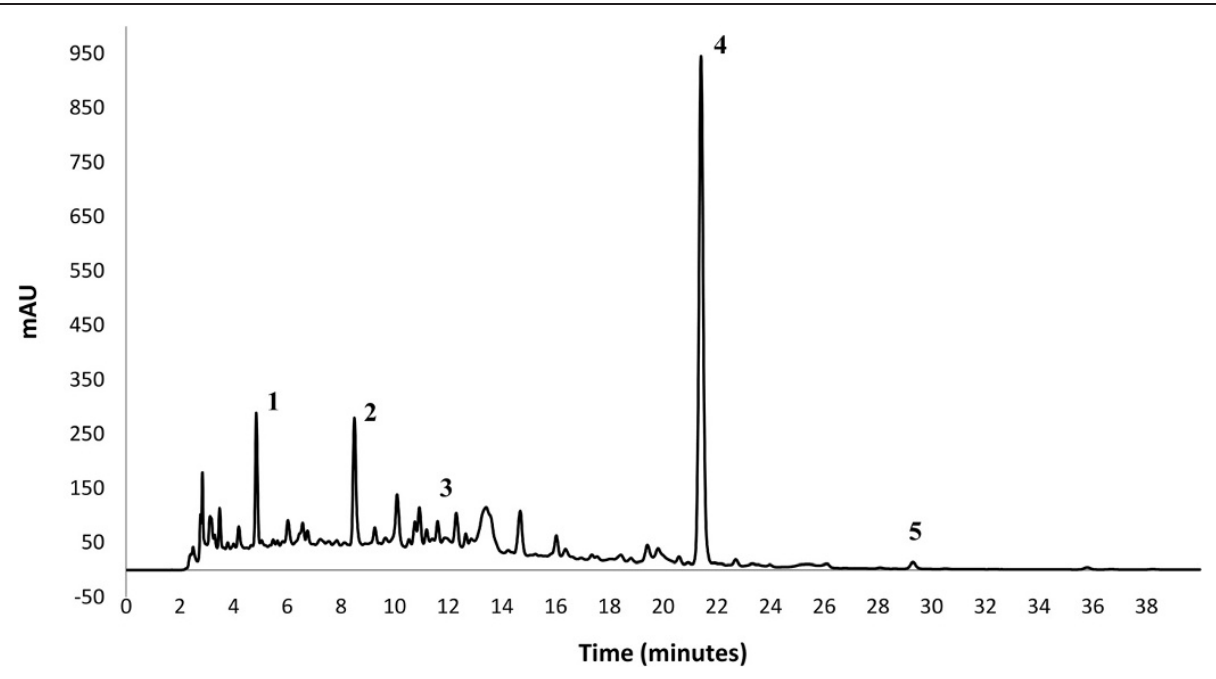

Figure 3 Chromatogram showing the phenolic compounds present in the red wine sample. 1. Gallic acid, 2. Chlorogenic acid, 3. Caffeic acid, 4. p-Coumaric acid, 5. Quercetin.

Several of the individual wine phenolic compounds inhibited the glucuronidation of testosterone at different efficiencies. The maximum inhibition was observed for quercetin, followed by 4-ethylphenol and caffeic acid. The serum concentrations of phenolic compounds that are commonly found in wine can be increased through supplementation such as with quercetin [23]. In one study, after supplementation, $1.5 \mu \mathrm{M}$ quercetin levels in plasma were reported [24]. This concentration of quercetin affected a 9\% reduction in UGT2B17 activity despite a high concentration of testosterone at $20 \mu \mathrm{M}$. The reported mean level of serum testosterone in adult males is $35.9 \mathrm{nM}$ [25]. Given the inhibition is competitive; these much lower concentrations of testosterone should result in higher inhibition of UGT2B17 by quercetin. Future studies are warranted to investigate the effects of red wine and its components at physiological levels of testosterone.

In addition, plasma concentrations of caffeic acid have been shown to increase after the consumption of red wine [26]. Given these increases in serum concentrations through supplementation it may be possible to further reduce testosterone metabolism through glucuronidation.

The phenolic compound 4-ethylphenol has been found in red wines to produce distinct aromas [27], as well as being produced by the spoilage of yeast, hence it can be

Table 1 Reduction in testosterone glucuronidation activity of UGT2B17 by the addition of phenolic compounds

\begin{tabular}{|c|c|c|c|}
\hline Initial testosterone concentration $(\mu \mathrm{M})$ & Test sample concentration & Test sample concentration $(\mu \mathrm{M})$ & Glucuronidation \% of control $( \pm S D)$ \\
\hline \multicolumn{4}{|l|}{ Screening study } \\
\hline 100 & 4-Ethylphenol & 750 & $78.9 \pm 1.131$ \\
\hline 50 & 4-Ethylphenol & 750 & $57.3 \pm 13.548$ \\
\hline 100 & Gallic acid & 250 & $91.01 \pm 10.946$ \\
\hline 100 & Caffeic acid & 250 & $78.65 \pm 5.685$ \\
\hline 100 & p-Coumaric Acid & 250 & NA \\
\hline 100 & Chlorogenic Acid & 250 & NA \\
\hline 100 & Quercetin & 250 & $28.01 \pm 2.800$ \\
\hline \multicolumn{4}{|l|}{ Low concentration study } \\
\hline 20 & Quercetin & 50 & $65.62 \pm 14.298$ \\
\hline 20 & Quercetin & 20 & $79.93 \pm 11.370$ \\
\hline 20 & Quercetin & 2 & $82.42 \pm 7.057$ \\
\hline 30 & Quercetin & 2 & $97.69 \pm 9.235$ \\
\hline 20 & Quercetin & 1.5 & $91.37 \pm 7.806$ \\
\hline
\end{tabular}

The results display the percentage change in the glucuronidation of testosterone over 60 mins by UGT2B17 in comparison to the uninhibited control. 
found in other dietary substances [28] and enters knowingly or unknowingly into the diet. 4-Ethylphenol has also been shown here to inhibit the glucuronidation of testosterone through the UGT2B17 enzyme. The inhibition of UGT2B17 by 4-Ethylphenol was found to be greater at the lower $50 \mu \mathrm{M}$ level of testosterone. However, at high initial testosterone concentrations above $150 \mu \mathrm{M}$ there was very little or no inhibition showing that increasing the concentration of testosterone will overcome the inhibiting compound. 4-Ethylphenol has been shown to be a substrate for UGT2B17 with a glucuronide being formed [13]; therefore it is likely that these compounds are acting competitively with the UGT2B17 enzyme.

Whilst it has been found that no correlation exists between the variations of the UGT2B17 genotype with alterations in circulating serum testosterone levels [2931], another study has found significant differences in circulating testosterone with an increase in individuals expressing no copy number of UGT2B17 compared to individuals with one or two copies of UGT2B17 [32]. It has yet to be determined if any direct inhibition of steroid glucuronidation enzymes could alter the levels of circulating serum testosterone in addition to altering the levels of testosterone excreted in urine. These results augment the previous study revealing that tea catechins can inhibit testosterone metabolism by supersomes containing UGT2B17 [17]. The ubiquitous presence of quercetin and other active flavonols, along with the catechins, in many foodstuffs indicate that any in vivo effects may be common. These effects, if found to occur in vivo, may have a pronounced effect on people with endocrine disorders or very low levels of endogenous testosterone, owing to high levels of receptor expression to compensate. A further aspect, although not studied here, is the potential interaction of quercetin-containing foodstuffs with drug metabolism as some drugs are metabolized via the action of UGT2B17 [33].

In conclusion it has been found that a commonly consumed dietary substance, red wine along with phenolic compounds present in red wine, inhibit testosterone glucuronidation. These results have also shown that although some of these compounds are not substrates of UGT2B17 they can inhibit the enzyme in supersomes.

\section{Competing interests}

The authors declare that they have no competing interests.

\section{Authors' contributions}

All authors contributed to the study design, data analyses and manuscript preparation. CJ completed the laboratory studies. All authors approved the final manuscript.

\section{Acknowledgements}

The authors thank Kingston University for funding for CJ.
Received: 2 May 2012 Accepted: 20 August 2012

Published: 7 September 2012

\section{References}

1. Walorczyk S, Drodyński D, Gnusowski B: Multiresidue determination of 160 pesticides in wines employing mixed-mode dispersive-solid phase extraction and gas chromatography-tandem mass spectrometry. Talanta 2011, 85(4):1856-1870.

2. Tariba B: Metals in wine-impact on wine quality and health outcomes. Biol Trace Elem Res 2011, 144:143-156.

3. Magrone T, Jirillo E: Potential application of dietary polyphenols from red wine to attaining healthy ageing. Curr Top Med Chem 2011, 11(14):1780-1796.

4. Rodrigo R, Miranda A, Vergara L: Modulation of endogenous antioxidant system by wine polyphenols in human disease. Clin Chim Acta 2011, 412 (5-6):410-424.

5. Eng ET, Williams D, Mandava U, Kirma N, Tekmal RR, Chen S: Suppression of aromatase (estrogen synthetase) by red wine phytochemicals. Breast Cancer Res Treat 2001, 67(2):133-146.

6. He S, Sun C, Pan Y: Red wine polyphenols for cancer prevention. Int $J$ Molec Sci 2008, 9(5):842-853.

7. Key J, Hodgson S, Omar RZ, Jensen TK, Thompson SG, Boobis AR, Davies DS, Elliott P: Meta-analysis of studies of alcohol and breast cancer with consideration of the methodological issues. Cancer Cause Control 2006, 17 (6):759-770.

8. Morgentaler A: Turning conventional wisdom upside-down: Low Serum testosterone and high-risk prostate cancer. Cancer 2011, 117 (17):3885-3888.

9. Djavan B, Eastham J, Gomella L, Tombal B, Taneja S, Dianat SS, Kazzazi A, Shore N, Abrahamsson PA, Cheetham P, Moul J, Lepor H, Crawford ED: Testosterone in prostate cancer: The Bethesda consensus. BJU Int 2012, 110:344-352.

10. Imamoto T, Suzuki H, Yano M, Kawamura K, Kamiya N, Araki K, Komiya A, Nihei $N$, Naya $Y$, Ichikawa $T$ : The role of testosterone in the pathogenesis of prostate cancer. Int J Urol 2008, 15(6):472-480.

11. Sutcliffe S, Giovannucci E, Leitzmann MF, Rimm EB, Stampfer MJ, Willett WC, Platz EA: A prospective cohort study of red wine consumption and risk of prostate cancer. Int J Cancer 2007, 120(7):1529-1535.

12. Chao C, Haque R, Van Den Eeden SK, Caan BJ, Poon KYT, Quinn VP: Red wine consumption and risk of prostate cancer: The California men's health study. Int J Cancer 2010, 126(1):171-179.

13. Turgeon D, Carrier JS, Chouinard S, Bélanger A: Glucuronidation activity of the UGT2B17 enzyme toward xenobiotics. Drug Metab Dispos 2003, 31:670-676

14. Ekström L, Gök E, Johansson M, Garle M, Rane A, Schulze JJ: Doping and genetic testing: Sex difference in UGT2B15 expression, testosterone glucuronidation activity and urinary testosterone/epitestosterone glucuronide ratio. Curr Pharm Pers Med 2012, 10:125-131.

15. Sten $T$, Finel $M$, Ask B, Rane $A$, Ekström L: Non-steroidal antiinflammatory drugs interact with testosterone glucuronidation. Steroids 2009, 74:971-977.

16. Jakobsson J, Ekström L, Inotsume N, Garle M, Lorentzon M, Ohlsson C, Roh HK, Carlström K, Rane A: Large differences in testosterone excretion in Korean and Swedish men are strongly associated with a UDPglucuronosyl transferase 2B17 polymorphism. J Clin Endocrinol Metab 2006, 91:687-693.

17. Jenkinson C, Petroczi A, Barker J, Naughton DP: Dietary green and white teas suppress UDP-glucuronosyltransferase UGT2B17 mediated testosterone glucuronidation. Steroids 2012, 77:691-695.

18. Waterhouse AL: Wine phenolics. Ann NY Acad Sci 2002, 957:21-36.

19. Chiyang H, Shehong L, Huwei L, Kean L, Feng L: Extraction of testosterone and epitestosterone in human urine using aqueous two-phase systems of ionic liquid and salt. J Chromatog A 2005, 1082(2):143-149.

20. Seemungal A, Petróczi A, Naughton DP: Ranking the efficacies of selected red wine phenolic anti-oxidants using reversed-phase HPLC. Eur Food Res Tech 2011, 233(5):781-789.

21. Ferris CF, Shtiegman K, King JA: Voluntary ethanol consumption in male adolescent hamsters increases testosterone and aggression. Physiol Behav 1998, 63:739-744.

22. Alomary AA, Vallée M, O'Dell LE, Koob GF, Purdy RH, Fitzgerald RL: Acutely administered ethanol participates in testosterone synthesis and increases testosterone in rat brain. Alcohol Clin Exp Res 2003, 27:38-43. 
23. Egert $S$, Wolffram $S$, Bosy-Westphal A, Boesch-Saadatmandi C, Wagner AE, Frank J, Rimbach G, Mueller MJ: Daily quercetin supplementation dosedependently increases plasma quercetin concentrations in healthy humans. J Nutr 2008, 138(9):1615-1621.

24. Conquer JA, Maiani G, Azzini E, Raguzzini A, Holub BJ: Supplementation with quercetin markedly increases plasma quercetin concentration without effect on selected risk factors for heart disease in healthy subjects. J Nutr 1998, 128:593-597.

25. Behre HM, Simoni M, Nieschlag E: Strong association between serum levels of leptin and testosterone in men. Clin Endocrinol 1997, 47:237-240.

26. Simonetti P, Gardana C, Pietta P: Plasma levels of caffeic acid and antioxidant status after red wine intake. J Agric Food Chem 2001, 49:5964-5968.

27. Pollnitz AP, Pardon KH, Sefton MA: Quantitative analysis of 4-ethylphenol and 4-ethylguaiacol in red wine. J Chromatogr A 2000, 31:101-109.

28. Barata A, Nobre A, Correia P, Malfeito-Ferreira M, Loureiro V: Growth and 4ethylphenol production by the yeast Pichia guilliermondii in grape juices. Am J Enol Vitic 2006, 57:133-138.

29. Ekstrom L, Schulze JJ, Guillemette C, Belanger A, Rane A: Bioavailability of testosterone enanthate dependent on genetic variation in the phosphodiesterase 7B but not on the uridine 5/-diphosphoglucuronosyltransferase (UGT2B17) gene. Pharmacogenet Genom 2011, 21:325-332.

30. Juul A, Sorensen K, Aksglaese L, Garn I, Rajpert-De Meyts E, Hullstein I, Hemmersbach P, Ottesen AM: A common deletion in the uridine disphosphate glucuronyltransferase (UGT) 2 B17 gene is a strong determinant of androgen excretion in healthy pubertal boys. J Clin Endocrinol Metab 2009, 94:1005-1011.

31. Swanson C, Mellström D, Lorentzon M, Vandenput L, Jakobsson J, Rane A, Karlsson M, Ljunggren O, Smith U, Eriksson A, Bélanger A, Labrie F, Ohlsson $C$ : The uridine diphosphate glucuronosyltransferase $2 \mathrm{~B} 15 \mathrm{D} 85 \mathrm{Y}$ and 2B17 deletion polymorphisms predict the glucuronidation pattern of androgens and fat mass in men. JCEM 2007, 92:4865-4872.

32. Yang TL, Chen XD, Guo Y, Lei SF, Wang JT, Zhou Q, Pan F, Chen Y, Zhang ZX, Dong SS, Xu XH, Yan H, Liu X, Qiu C, Zhu XZ, Chen T, Li M, Zhang H, Zhang L, Drees BM, Hamilton JJ, Papasian C, Recker RR, Song XP, Cheng J, Deng HW: Genome-wide copy-number-variation study identified a susceptibility gene, UGT2B17, for osteoporosis. Am J Hum Genet 2008, 83:663-674.

33. Wong NS, Seah EZH, Wang LZ, Yeo WL, Yap HL, Chuah B, Lim YW, Ang PCS, Tai BC, Lim R, Goh BC, Lee SC: Impact of UDP-gluconoryltransferase 2B17 genotype on vorinostat metabolism and clinical outcomes in Asian women with breast cancer. Pharmacogenet Genom 2011, 21(11):760-768.

doi:10.1186/1475-2891-11-67

Cite this article as: Jenkinson et al:: Red wine and component flavonoids inhibit UGT2B17 in vitro. Nutrition Journal 2012 11:67.

\section{Submit your next manuscript to BioMed Central and take full advantage of:}

- Convenient online submission

- Thorough peer review

- No space constraints or color figure charges

- Immediate publication on acceptance

- Inclusion in PubMed, CAS, Scopus and Google Scholar

- Research which is freely available for redistribution 